\title{
COMPARATIVE ASSESSMENT OF TROPOSPHERIC MODELS ON BASELINE PRECISION IN A LOCAL GPS NETWORK
}

\author{
DOI: 10.31618/ESU.2413-9335.2019.1.62.87 \\ Bazarzagd Lkhagvasuren ${ }^{1}$, \\ Munkh-Ireedui Khasbazar', \\ Zorigtbaatar Amarsaikhan ${ }^{2}$ \\ I- Department of Land Management, Mongolian University of Life Sciences, \\ Zaisan, 17024, Ulaanbaatar city, Mongolia \\ 2 - Department of Geodesy, Agency for Land Administration and Management, \\ Geodesy and Cartography, \\ 15170, Ulaanbaatar city, Mongolia
}

\begin{abstract}
.
Satellite based positioning systems are widely used for various applications. There are several error sources that causes the estimated position and time measurements from satellite based positioning systems' receivers such as GPS and GNSS to be inaccurate. The one of the significant error sources is tropospheric delay. The troposphere is the lowest layer of the atmosphere near the earth that causes the largest error source of pseudo-lite signal as it propagates through the lower troposphere, and the thickness of it is 9-16 km. The GPS signal path through troposphere depends on temperature, pressure, height, latitude, and humidity (Gurtner, et al. 1989). It is necessarily to correct the signal delay caused by the troposphere. This paper reveals the importance of the tropospheric delay modeling for precise baseline parameter estimation by assessment of tropospheric delay models, and mapping function used to model the tropospheric delay in Mongolia at different elevation angles $\left(0^{\circ}, 5^{\circ}, 10^{\circ}, 15^{\circ}\right.$, and $\left.20^{\circ}\right)$. The paper also discusses the advantages and limitations of these models. Trimble Geomatic Office (TGO) software is used to analyze the data in the current study.
\end{abstract}

Keywords: tropospheric delay models, baseline precision, mapping function, GPS, error

\section{INTRODUCTION}

The indispensability of the Global Positioning System (GPS), or generally the Global Navigation Satellite System (GNSS), in modern geodetic techniques and other disciplines has necessitated investigations into the various errors affecting the system. Following the emission of signals by GNSS satellites, their propagation through the atmosphere to the receiver is delayed by the different refractive indices of the various atmospheric layers (Shrestha, et al. 2003). Two main atmospheric subdivisions can be distinguished based on the way radio waves are propagated. These are: the ionosphere and the troposphere.

The ionosphere is the upper part of the atmosphere and is a region of charged particles with a large number of free electrons. It is a dispersive medium with a frequency-dependent propagation delay. The ionospheric bias can be mitigated using dual frequency GPS receivers. The troposphere however, is the lowest part of the electrically-neutral region of the atmosphere spanning from the earth's surface to about $8 \mathrm{~km}$ at the poles and $16 \mathrm{~km}$ over the equator (Rizos, et.al 1997). It is nondispersive in nature and thus delays signals in a manner completely independent of their frequencies. The troposphere is an unstable layer, with significant atmospheric turbulence due to vertical convection currents, particularly within its boundary layer i.e. the lowest 2 $\mathrm{km}$ of the troposphere (Kleijer, et.al 2004). Tropospheric delays can be separated into two main components (Hofmann-Wellenhof, et.al 2008).

Unless tropospheric delay effects are corrected, the height component of positions would be inaccurate especially in space-geodesy applications including sealevel monitoring, post-glacial rebound measurements, earthquake-hazard mitigation, and crustal motion studies (Shrestha, 2003). These considerations are critical reasons for tropospheric delay modelling. It also gives credence to the incorporation of tropospheric models in most commercial GNSS processing software. The availability of different tropospheric models is a further premise for probing into the impact of each of these models on baseline processing.STUDY AREA

We used the result of dual frequency static measurement of nine GPS stations which are located Ulaanbaatar, Darkhan, Erdenet, Khovd and Arvaikheer in Mongolia. The network consists of 9 stations and various different length of 36 baselines as shown in Figure 1. The DA01, ER01, UB01, UB02, and 5026 stations are permanent GPS stations. This network gives an opportunity to analyze various baseline lengths ranging from approximately $1 \mathrm{~km}$ to $1300 \mathrm{~km}$. 


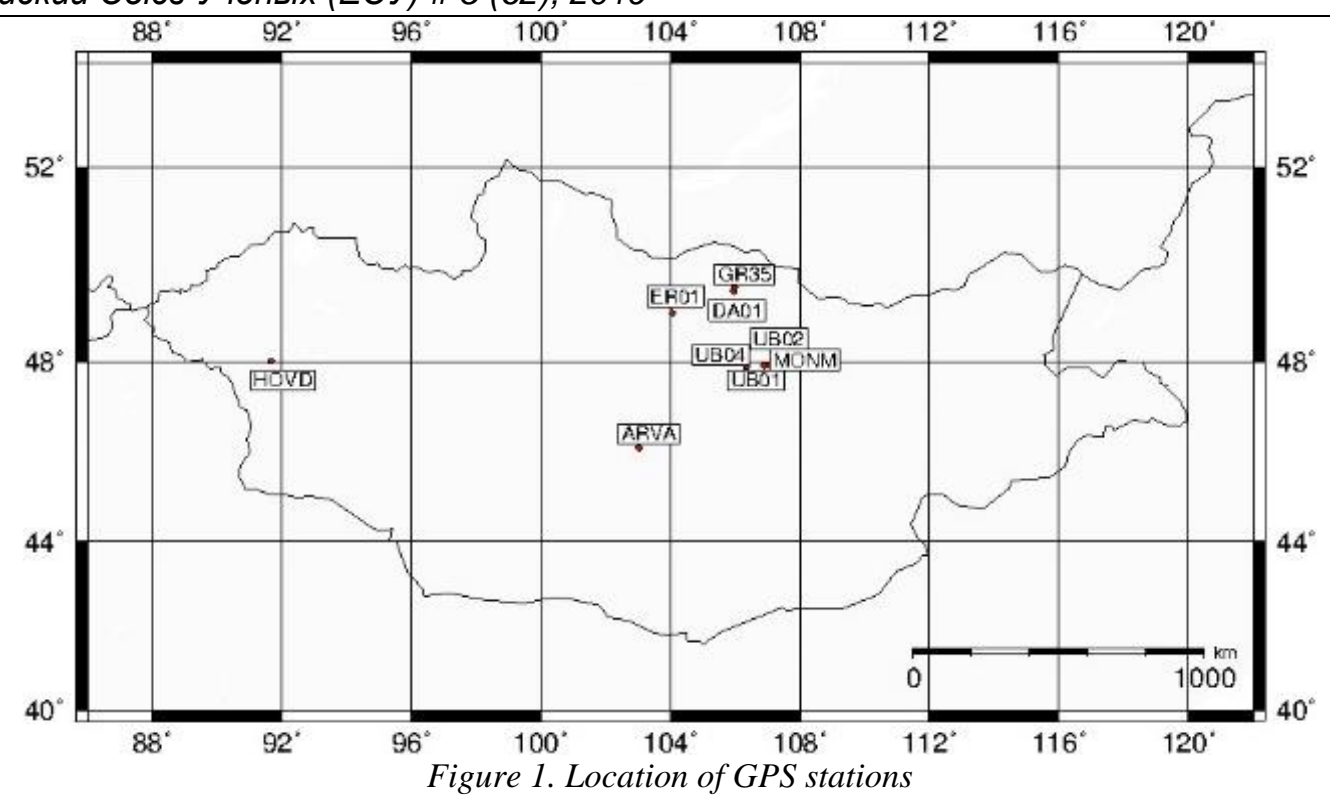

METHODOLOGY The workflow is showed in Figure 2: the first stage is to derive the tropospheric error in the reference stations from continuous observations; and second is to build proper error interpolation models; finally, the interpolated tropospheric error would be analyzed and accordingly the performance of interpolation models could be evaluated. Each baseline was treated as an individual session and processed using the following tropospheric models:
- Saastamoinen model /SAAS/

- Hopfield model /HOP/

- Niell model /NIE/

- No model applied /NONE/

These models have a variation in accuracy. The effect of an error in all models of the tropospheric delay increasing with the elevation angles.DATA

The location of stations, dual frequency receivers and their antenna types are shown in Table 2.

Characteristics of GPS data used in this research

\begin{tabular}{|c|c|c|c|c|c|c|c|}
\hline $\begin{array}{c}\text { Station } \\
\text { name }\end{array}$ & $\begin{array}{c}\text { Station } \\
\text { code }\end{array}$ & $\begin{array}{c}\text { Lattitude, } \\
\text { deg (N) }\end{array}$ & $\begin{array}{c}\text { Longitude, } \\
\text { deg (E) }\end{array}$ & $\begin{array}{c}\text { Height, } \\
\mathrm{m}\end{array}$ & $\begin{array}{c}\text { Receiver } \\
\text { type }\end{array}$ & Antenna type & $\begin{array}{c}\text { Antenna } \\
\text { height, } \\
\mathrm{m}\end{array}$ \\
\hline Arvaikheer & ARVA & $\begin{array}{c}46^{\circ} 07^{\prime} \\
17.48^{\prime}\end{array}$ & $\begin{array}{c}103^{\circ} 01^{\prime} \\
16.05^{\prime}\end{array}$ & 1590.276 & $\begin{array}{c}\text { LEICA } \\
\text { GX1230GG }\end{array}$ & LEIAX1202GG & 1.420 \\
\hline Darkhan & DA01 & $\begin{array}{c}49^{\circ} 28^{\prime} \\
52.75^{\prime}\end{array}$ & $\begin{array}{c}105^{\circ} 56^{\prime} \\
36.60^{\prime}\end{array}$ & 692.655 & $\begin{array}{c}\text { Trimble } \\
\text { 4000SSI }\end{array}$ & TRM29659.00 & 0.000 \\
\hline Erdenet & ER01 & $\begin{array}{c}49^{\circ} 01^{\prime} \\
46.40^{\prime}\end{array}$ & $\begin{array}{c}104^{\circ} 03^{\prime} \\
44.39^{\prime}\end{array}$ & 1301.849 & $\begin{array}{c}\text { Trimble } \\
\text { 4000SSI }\end{array}$ & TRM29659.00 & 0.000 \\
\hline GR35 & GR35 & $\begin{array}{c}49^{\circ} 33^{\prime} \\
43.29^{\prime}\end{array}$ & $\begin{array}{c}105^{\circ} 59^{\prime} \\
12.48^{\prime}\end{array}$ & 677.508 & $\begin{array}{c}\text { LEICA } \\
\text { GX1230GG }\end{array}$ & LEIAX1202GG & 1.384 \\
\hline Khovd & HOVD & $\begin{array}{c}47^{\circ} 57^{\prime} \\
46.78^{\prime}\end{array}$ & $\begin{array}{c}91^{\circ} 37^{\prime} \\
28.69^{\prime}\end{array}$ & 1407.966 & $\begin{array}{c}\text { LEICA } \\
\text { ATX1230 }\end{array}$ & LEIATX1230GG & 1.040 \\
\hline MONM & MONM & $\begin{array}{c}47^{\circ} 54^{\prime} \\
58.58^{\prime}\end{array}$ & $\begin{array}{c}106^{\circ} 53^{\prime} \\
58.88^{\prime}\end{array}$ & 1288.681 & $\begin{array}{c}\text { LEICA } \\
\text { GRX1200+ }\end{array}$ & LEIAR10 & 0.076 \\
\hline UBO1 & UB01 & $\begin{array}{l}47^{\circ} 55^{\prime} \\
16.83^{\prime}\end{array}$ & $\begin{array}{c}106^{\circ} 54^{\prime} \\
31.67^{\prime \prime}\end{array}$ & 1278.199 & $\begin{array}{c}\text { Trimble } \\
\text { 4000SSI }\end{array}$ & TRM29659.00 & 0.000 \\
\hline UBZUUN & UB02 & $\begin{array}{c}47^{\circ} 54^{\prime} \\
55.70^{\prime}\end{array}$ & $\begin{array}{c}106^{\circ} 58^{\prime} \\
19.05^{\prime}\end{array}$ & 1290.395 & $\begin{array}{c}\text { Trimble } \\
\text { 4000SSI }\end{array}$ & TRM29659.00 & 0.000 \\
\hline 5026 & UB04 & $\begin{array}{c}47^{\circ} 53^{\prime} \\
06.82^{\prime}\end{array}$ & $\begin{array}{c}106^{\circ} 20^{\prime} \\
02.30^{\prime \prime}\end{array}$ & 1681.398 & $\begin{array}{c}\text { Trimble } \\
\text { 4000SSI }\end{array}$ & TRM29659.00 & 0.000 \\
\hline
\end{tabular}

\section{ANALYSIS AND RESULTS}

According to the Mongolian National Geodetic Accuracy Standards and Specifications for GPS/GLONASS Relative Positioning Technique, regarding as its lengths we classified the baselines into five categories illustrates in Table 1. For used network, there are 36 baselines in which 8 are AA class, 7 are A class, 14 are B class, 3 are C-1 class and 4 are C-2 class. 
Table 1 .

Baseline classification

\begin{tabular}{|c|c|}
\hline Baseline classification & Baseline lenght \\
\hline AA & longer than 500км \\
\hline A & $250-500 \mathrm{~km}$ \\
\hline B & $100-250 \mathrm{~km}$ \\
\hline C-1 & $20-100 \mathrm{~km}$ \\
\hline C-2 & shorter than $20 \mathrm{~km}$ \\
\hline
\end{tabular}

We used Trimble Geomatics Office (TGO) at the processing stage, a popular Commercial GNSS processing software, which is one of the various Trimble products used in over 100 countries around the world (Neal, 2008). General flowchart of data processing in TGO is shown as Fig.2.

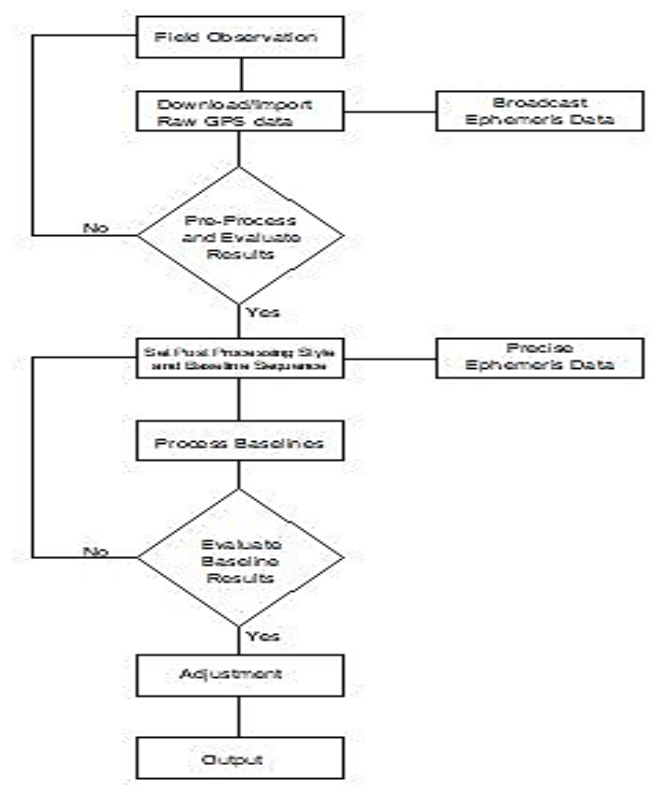

Figure 2. Flowchart of data processing

In the following analyses, the discrepancies in the three coordinate components compared to the reference coordinates were firstly calculated. The performance of each standard tropospheric model can be characterized by the Root Mean Square Error (RMSE). It can be seen from Table 3 that by applying any standard tropo- spheric model in the baseline estimation step, accuracies of coordinates in both horizontal and vertical components are improved. In addition, all RMSE values indicate that the Saastamoinen and the Hopfield models tend to produce more reliable baseline results than the Simplified Hopfield model.

Table. 3.

Accuracy assessment in used models

\begin{tabular}{|c|c|c|c|r|}
\hline \multirow{2}{*}{ Baseline classes } & \multicolumn{3}{|c|}{ RMSE, M } \\
\cline { 2 - 4 } & HOP & SAAS & NIE & None \\
\hline AA & 0.0218 & 0.0229 & 0.0229 & 0.4364 \\
\hline A & 0.0115 & 0.0113 & 0.0115 & 0.2120 \\
\hline B & 0.0263 & 0.0266 & 0.0276 & 0.0925 \\
\hline C-1 & 0.0147 & 0.0093 & 0.0093 & 0.0243 \\
\hline C-2 & 0.0188 & 0.0188 & 0.0188 & 0.0225 \\
\hline
\end{tabular}




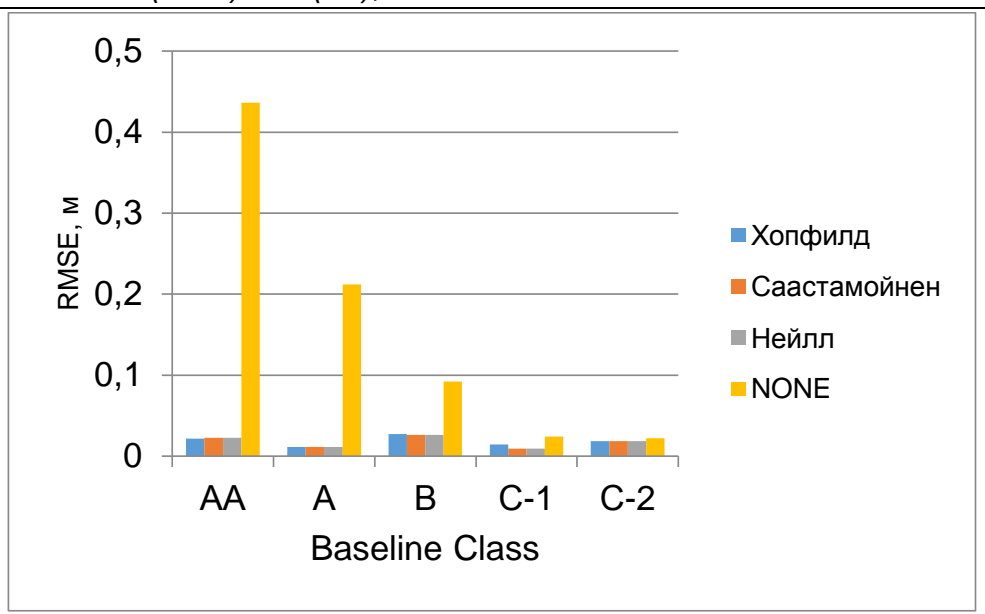

Figure 3. Error in baseline lengths

Table 4.

Elevation angle and its accuracy

\begin{tabular}{|c|c|c|c|}
\hline Elavation angle & SAAS & HOP & NIE \\
\hline 0 & 0.022 & 0.690 & 0.453 \\
\hline 5 & 0.021 & 0.021 & 0.416 \\
\hline $\mathbf{1 0}$ & $\mathbf{0 . 0 1 7}$ & $\mathbf{0 . 0 1 7}$ & $\mathbf{0 . 4 0 7}$ \\
\hline 15 & 0.018 & 0.018 & 0.416 \\
\hline 20 & 0.021 & 0.021 & 0.423 \\
\hline
\end{tabular}

\section{References}

1. B.Hofmann-Wellenhof, H.Lichtenegger, J.Collins, GPS theory and practice, $5^{\text {th }}$ edition, New York, pp.106-115, 2009

2. Rizos.M, Businger.ST, GPS Meteorology: Mapping zenith wet delays onto precipitable water, Journal of Applied Meteorology, Vol.33, pp.379-386, 1997

3. Celestino.C.C, Sousa.C.T, Yamaguti.W, Kuga.H.W, Evaluation of Tropospheric and Ionospheric effects on the Geographic localization of data collection platforms, Hindawi Publishing, Vol.2007, No.32514, pp.1155-1166, 2007

4. Shrestha.S, Prapod.C, Impact of different tropospheric models on GPS baseline accuracy: Case study in Thailand, Journal of Global Positioning Systems, Vol.4, No.1, pp.36-40, 2003

5. Chang.C.C, Neal.C.L, Testing on tropospheric modeling for GPS tracking stations in Taiwan, Bulletin Geodesique, Vol.64, pp.127-159, ROC, 2008

6. Kleijer.K, Improvements in GPS tropospheric delay estimation with numerical weather prediction, $\mathrm{PhD}$ thesis, University of New Brunswick, Canada, 2004

7. Davis.J.L, Herring.T.A, Shapiro.I.I, Effects of atmospheric modeling errors on estimates of baseline length, Radio Science, Vol.20, pp.1593-1607, 1985

Station heights derived from adjustment

\begin{tabular}{|c|c|c|c|c|c|}
\hline Ng & $\begin{array}{c}\text { Station } \\
\text { name }\end{array}$ & NONE & HOP & SAAS & NIE \\
\hline 1 & ERDENET & 1298.727 & 1298.792 & 1298.788 & 1298.721 \\
\hline 2 & DARKHAN & 690.039 & 689.866 & 689.858 & 690.015 \\
\hline 3 & 5026 & 1678.424 & 1678.608 & 1678.609 & 1678.432 \\
\hline 4 & GR35 & 674.77 & 674.705 & 674.693 & 674.75 \\
\hline 5 & MONN & 1285.731 & 1285.776 & 1285.775 & 1285.732 \\
\hline 6 & UBO1 & 1275.403 & 1275.403 & 1275.403 & 1275.403 \\
\hline 7 & UBZUUN & 1287.584 & 1287.591 & 1287.59 & 1287.584 \\
\hline 8 & ARYA & 1587.501 & 1587.525 & 1587.523 & 1587.502 \\
\hline
\end{tabular}

